\title{
Mullerian-Renal-Cervical Spine Syndrome
}

National Cancer Institute

\section{Source}

National Cancer Institute. Mullerian-Renal-Cervical Spine Syndrome. NCI Thesaurus. Code C131010.

A condition characterized by Mullerian duct aplasia, unilateral renal dysplasia, and cervicothoracic anomalies. Other associated findings may include skeletal abnormalities (scoliosis, vertebral anomalies, rib malformations, spina bifida), and face and limb malformations (brachymesophalangy, ectrodactyly). Heart malformations may include valvular pulmonary stenosis, aortopulmonary window, atrial septal defect, and/or tetralogy of Fallot. Putative candidate genes such as HNF1B (17q12), LHX1 (17q12), SHOX (Xp22.33 and Yp11.32), TBX6 ( 16p11.2), and ITIH5 (10p14) may be implicated. 